\title{
PERFORMANCES OF COMBINED SHUNT PASSIVE AND SERIES ACTIVE FILTERS
}

\author{
K. ALIOUANE*
}

\begin{abstract}
Harmonics generated by converters have become a serious problem for the $A C$ mains as they can only be removed by using bulky passive filters. Besides, the harmonic compensation by shunt passive filters may cause undesirable interferences such as resonance with the AC mains. To solve this problem some authors have proposed a combined system of a shunt passive filter and a series active filter. This system is self-adaptable and only small power active filter is needed. The choice of the control algorithm, together with the $\mathrm{AC}$ mains and non-linear load parameters determine its performances.

In this paper the compensation characteristics of this system are studied. The filter control system with some peculiar features is detailed, simulation and experimental results obtained by a single-phase prototype are presented.
\end{abstract}

\section{KEY WORDS}

Harmonic, Resonance, Passive Filter, Active Filter, PWM Control, IGBT

\section{NOMENCLATURE}

- is : supply current

- $v_{F}$ : passive filter voltage

- vc : active filter voltage

- iL : Load current (A)

- iLh : load harmonic current

- ish : source harmonic current

- Vc: series active filter voltage

- Q : quality factor

- fc : cut-off frequency

${ }^{\star}$ Dir. of . Electromagnetic Systems Lab., Dpt. of Electrical Engineering, EMP, Bordj-elBahri Alger, Algeria 


\section{INTRODUCTION}

Non-linear loads such as diode or thyristor rectifiers produce current harmonics which cause interference with the AC mains. Passive filters are conventionally used to suppress the harmonic distortion, but these filters have some inherent disadvantages:

- the passive filter may cause parallel resonance with the AC source. Therefore amplification of the harmonic currents on the source side at specific frequencies occurs.

- the passive filter generates series resonance with the $A C$ source. Therefore significant voltage harmonics on the $\mathrm{AC}$ source can appear.

All these undesirable characteristics can be avoided by using active filters[1]. However the shunt active filters present certain problems in terms of their practical application[2] :

- large VA rating PWM converters with rapid current response and low losses are not easy to design.

- initial and running costs of such apparatus are significant compared with the LC filters.

To solve these problems, some authors have proposed a combined system of a shunt passive and small rated series active filters[3]. The choice of the control algorithm, the nonlinear load and the Ac mains parameters determine its performances[4]. After describing the circuit and the control principle of the filter, compensation characteristics are discussed. Some simulation and experimentation results which confirm the analytical conception of the system are presented.

\section{SYSTEM CONFIGURATION}

Figure 1 gives the proposed system. The non-linear load is a single-phase thyristor bridge rectifier. The shunt passive filter consists of $3^{\text {rd }}, 5^{\text {th }}, 7^{\text {th }}$ harmonic tuned LC filters connected in parallel with the load. The PWM converter is inserted in series with the source impedance through a current transformer used to match the current rating of the PWM converter with that of the AC system.

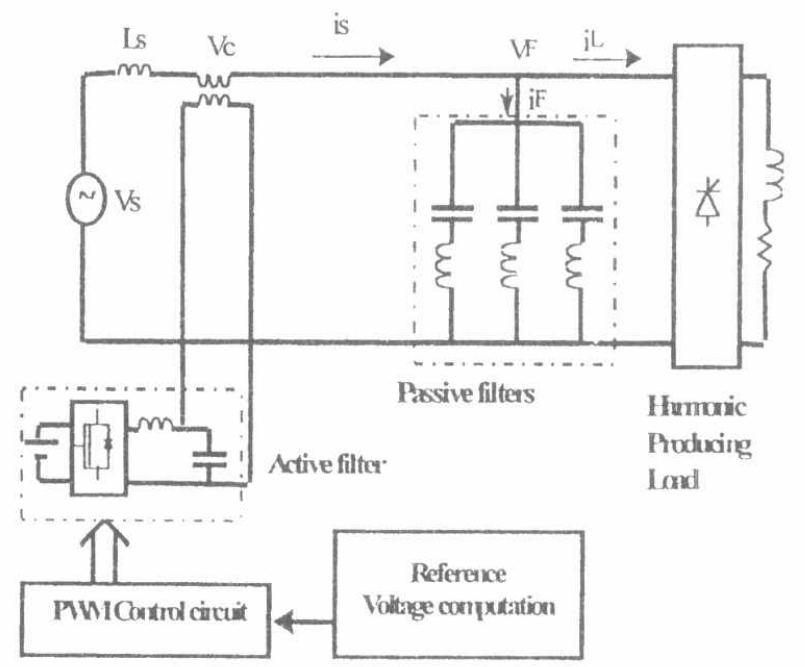

Fig. 1 : Combined system 


\begin{tabular}{|l|l|}
\hline $\mathrm{CS}-8$ & 3 \\
\hline
\end{tabular}

\begin{tabular}{|l|l|l|l|}
\hline $3^{\text {rd }}$ & $\mathrm{C} 3=66 \mu \mathrm{F}$ & $\mathrm{L} 3=17 \mu \mathrm{H}$ & $\mathrm{Q}=15$ \\
\hline $5^{\text {th }}$ & $\mathrm{C} 5=24 \mu \mathrm{F}$ & $\mathrm{L} 5=17 \mu \mathrm{H}$ & $\mathrm{Q}=15$ \\
\hline $7^{\text {th }}$ & $\mathrm{C} 7=50 \mu \mathrm{F}$ & $\mathrm{L} 7=4.2 \mu \mathrm{H}$ & $\mathrm{Q}=15$ \\
\hline
\end{tabular}

Table 1 : Shunt passive filters parameters

\section{OPERATING PRINCIPLE AND CONTROL SCHEME}

The equivalent circuit is shown in figure 2 where $\mathrm{Zs}$ indicates the line impedance and Zf the passive filter impedance. For the purpose of this analysis, the load can be typically considered as a current generator. Let us consider also the PWM converter like a controllable voltage source.

From figure 2 we can obtain following equations :

$$
\begin{aligned}
\underline{I}_{s h}=\left(\underline{V}_{s h}+\underline{Z}_{f} \cdot \underline{I}_{L h}-\underline{V}_{c h}\right) /\left(\underline{Z}_{s}+\underline{Z}_{f}\right) \\
\text { Then } \underline{I}_{s h}=0 \quad \text { if } \quad \underline{V}_{c h}=\underline{V}_{s h}+\underline{Z}_{f} \cdot \underline{I}_{L h}
\end{aligned}
$$

where Vsh represents the source voltage harmonics, Vch the series active filter voltage and IL.h the load current harmonics.

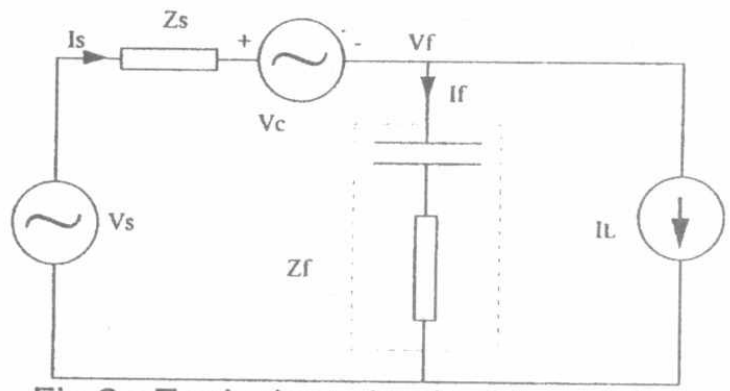

Fig 2 : Equivalent circuit of the system

A control scheme using equation (2) is impractical because Vsh cannot be measurable. So the PWM converter has to be operated in order to present a negligible (zero) impedance at the fundamental frequency and a high resistance for source or load harmonics[5].

Then the output voltage of the series active filter $V_{c}$ can be given by :

$$
\mathrm{Vc}=\mathrm{R}^{*} \text { Ish }
$$

Where Ish is calculated as indicated in the block scheme of figure 3.

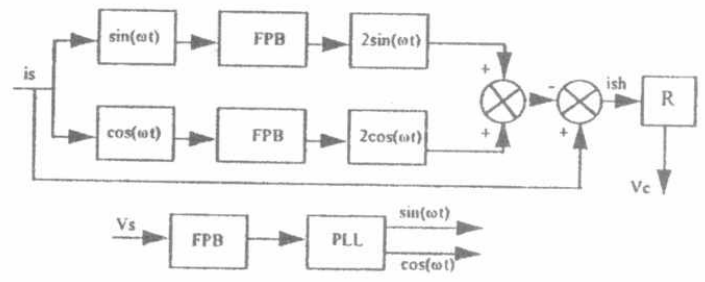

Fig. 3 : Control circuit of active filter 


\begin{tabular}{|l|l|}
\hline CS-8 & 4 \\
\hline
\end{tabular}

To separate the fundamental component of is from its harmonic components Ish, a notch filter is needed. At this propose, a rotating-frame transformation similar to that adopted in [6] can be used as indicated in the block scheme of figure 3. Source current components inphase and in quadrature with the supply $\vee . .$. age fundamental are calculated, filtered and back converted.

With this method, the variation of the source frequency has not any effect on the circuit constants of the notch filter.

This solution requires the generation of the unit vectors $\cos (\omega t)$ and $\sin (\omega t)$ which can be obtained from the line voltage by PLL. circuit shown in fig. 3.

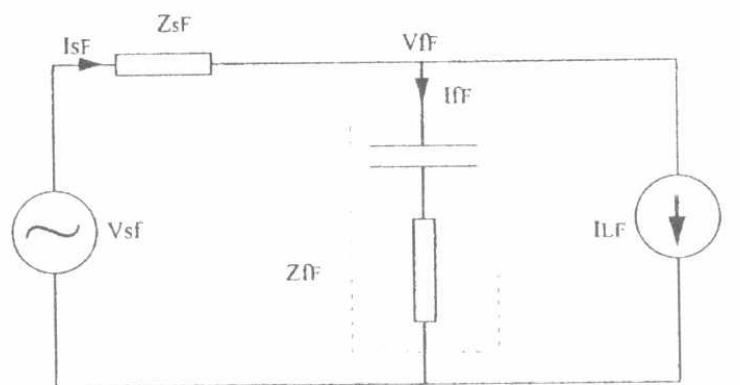

(a) at fundamental

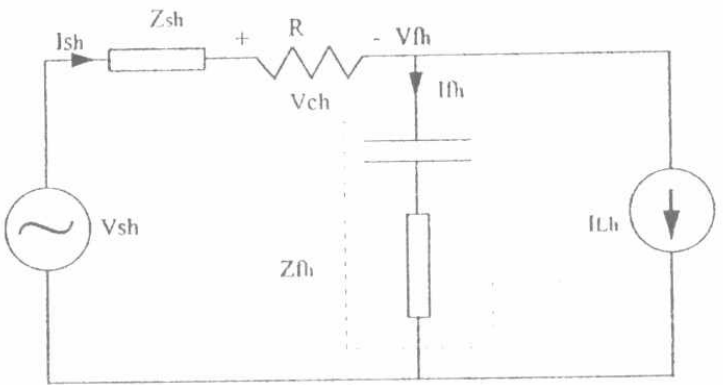

(b)for harmonics

Fig. 4 : Equivalent circuit for fundameratal and harmonics

The superposition principle gives the equivalent circuits for the fundamental frequency and harmonics as in figures $4 \mathrm{a}$ and $4 \mathrm{~b}$. From equations (1) and (3) for $V s h=0$, the harmonic compensation characteristics Ish/ILh can be given as follows :

$$
I s h / I L h=Z f /(Z f+Z s+R)
$$

The amplitude of (4) against frequency is shown in figure 5 for different values of R. Note that when $\mathrm{R}=0$, the shunt passive filter falls in parallel resonance.

Equation (4) indicates that the ideal case of perfect harmonic isolation is achieved when $R$ is infinite. The variation of $R$ with respect to Ish/IL1 is illustrated in figure 6 , where it can be noticed that the harmonic compensation obtained for the values of $\mathrm{R}$ superior to 20 is not much more important. On the other hand, equation (3) shows that the required rating of the series active filter increases when $R$ is larger. The reason is that the variation of $R$ and Ish/IL1 are not in the same proportion.

In the same manner as equation (4) has been obtained, the harmonic current flowing from source to the shunt passive filter can be given from equation (1) and (3) when ILh=0.

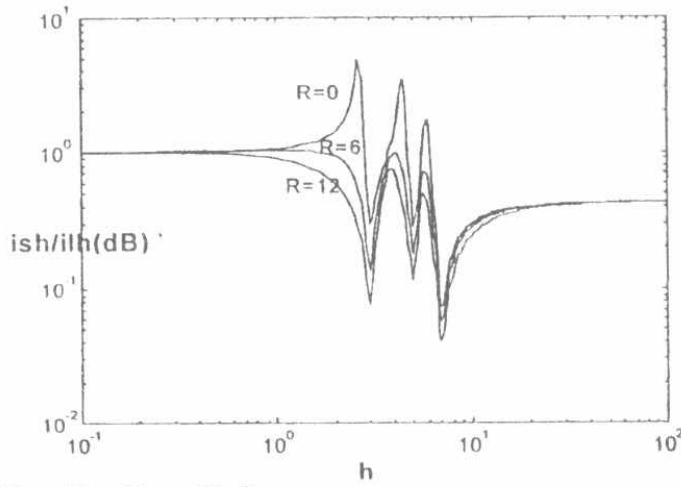

Fig. 5 : Parallel resonance

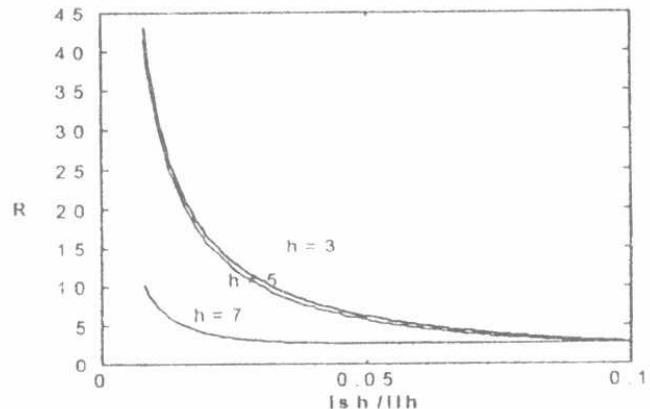

Fig. 6 : Gain K as function of Ish/IL1 
Figure 7 shows the normalised magnitude curve of the system impedance, $Z 1 / Z 0$ for $R=0$, $R=6, R=12$, where $Z 0$ is rated impedance.

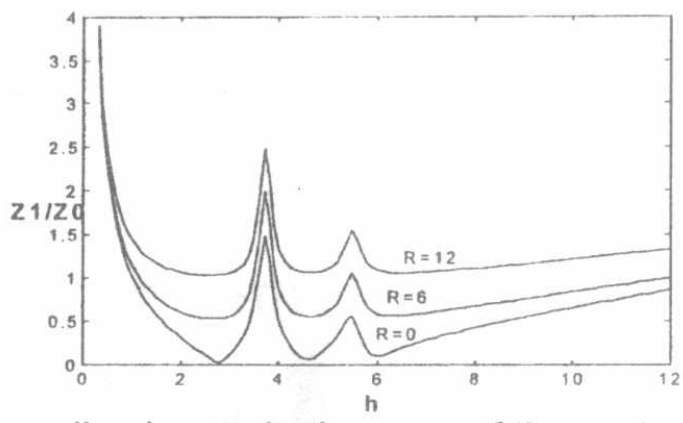

Fig. 7 : Normalised magnitude curve of the system impedance

It is clear that when $R=0$ the shunt passive filter falls in series resonance with the source impedance when $Z 1 / Z 0$ is close to zero. Whilst thanks to the series active filter $(R \neq 0)$ the series resonance disappears and system impedance for harmonics increases.

\section{SIMULATION RESULTS}

The proposed system shown in figure 1 is simulated in order to verify the control algorithm. The following parameters are used in these simulations: The passive filter configuration is according to figure 1 and table 1.

- Load : 2 kVA.

- Carrier frequency of the PWM inverter : $15 \mathrm{kHz}$.

- DC voltage of the PWM inverter : 100 Volts.

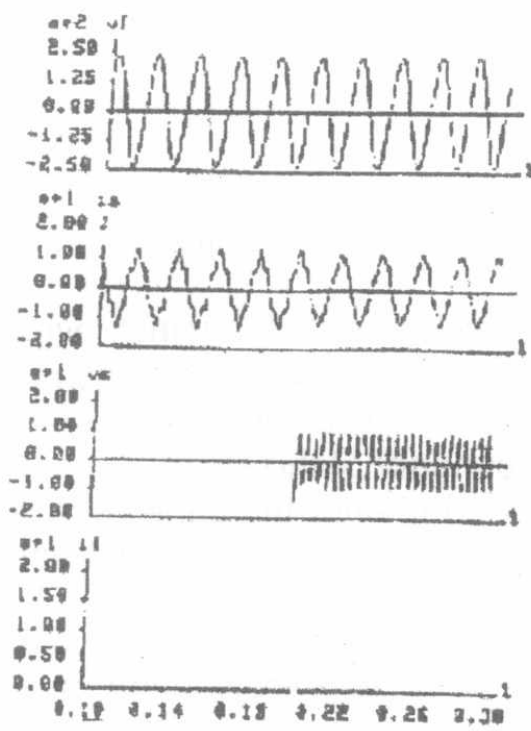

(a) : without load

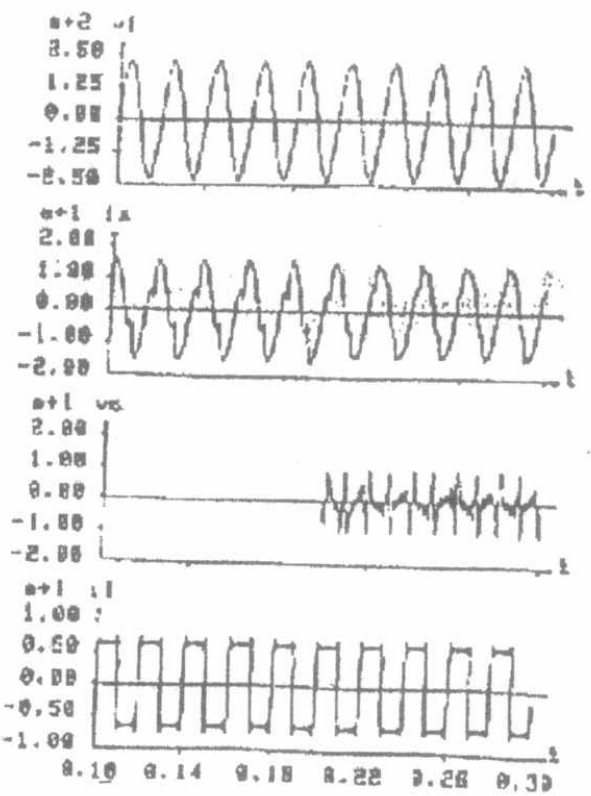

(b) : with load

Fig. 8 : Simulation results

From top to bottom : - vf : filter voltage (V) - is : supply current (A)

- vc : active filter voltage (V) - iL : Load current (A) 
Figure $8 \mathrm{a}$ shows the simulation waveforms with no load when the source voltage contains $5 \%$ of harmonics, before and after the series active operated. Corresponding spectrums of the current source are given in figure $9 a$.

Figure $8 b$ shows the compensation characteristics for $L s=2 \%, f c=5 H z\left(F(p)\right.$ is a $2^{\text {nd }}$ order LPF figure 3 ) and $R=0$. Figure $9 b$ compares the harmonic content of the source current without and with series active filter.

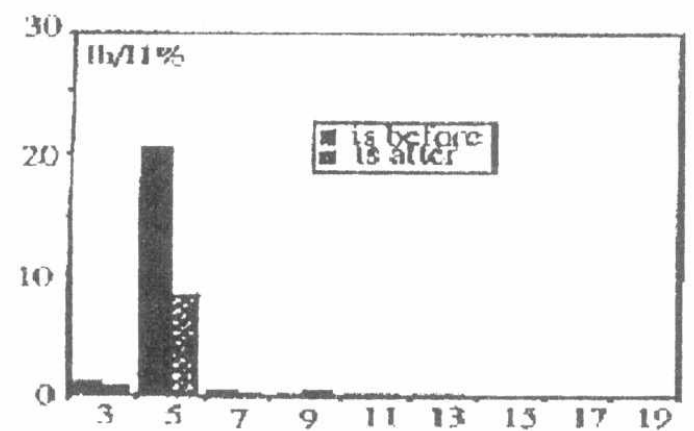

(a): without load

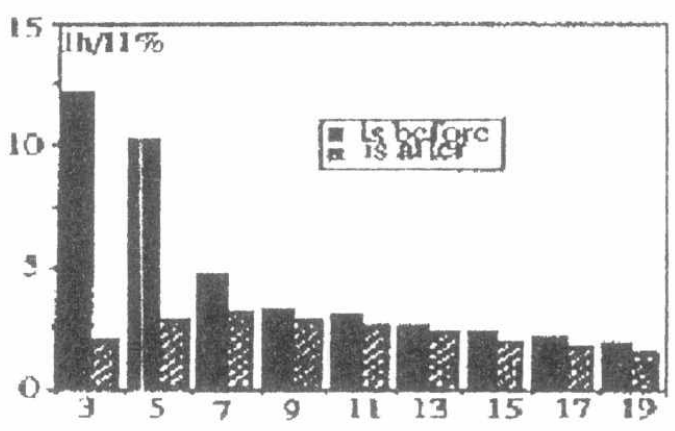

(b) : with load

Fig. 9 : Spectrum of the source current

\section{EXPERIMENTATION RESULTS}

A single-phase low-power model consisting of a $2 \mathrm{kVA}$ thyristor rectifier as the non-linear load, the passive filter configuration according to the figure 1 and table 1 has been developed in our laboratory. The experiments were done under the following conditions :

$\mathrm{K}=10$

Carrier frequency of the PWM inverter : $15 \mathrm{kHz}$.

DC voltage of the PWM inverter: 100Volts.

Capacitance of the DC capacitor was $1500 \mu \mathrm{F}$.

The losses of the PWM inverter used compensated by a single-phase diode rectifier in order to maintain the capacitor's voltage.

The voltage-source PWM inverter used in series active filter is protected against overvoltage and over-current by the following means : all the power IGBT's of the upper legs are tuned off in order to release the DC capacitor from the secondary of the current transformer, while those of the lower legs are tuned on to short-circuit the secondary of the CT.

Figure 10 shows the experimental waveforms with no load before and after the series active filter was operated. With the series active filter the source current becomes sinusoidal and no harmonic voltage appears at the terminals of the shunt passive filter.

Figure 11 shows the experimental waveform with the load. The source current is quite enough sinusoidal and load current harmonics are absorbed by the shunt passive filter once the PWM converter operates. 


\begin{tabular}{|l|l|}
\hline CS-8 & 7 \\
\hline
\end{tabular}

\section{CONCLUSION}

In this paper a combination of passive and active series filter is proposed. This system can be considered as a solution to the problems caused by the passive filter used alone. A simple and practical control scheme for the system is used. The control method is confirmed by numerical simulation and experimentation. The results obtained are satisfying. The series active filter improves the filtering characteristics of the passive filter because it acts as a harmonic isolator between the source and the load.

\section{References}

[1]. L. Gyugyi and E.C. Strycula, "Active ac power filter", IEEE-IAS Annual Meeting, pp. 529535, 1976.

[2]. Thanh-nam Lê, "Performance of voltage-source active filters", EPE conf. Firenze (Italy), vol.3, pp. 1-5,1991.

[3]. F. Zheng, H. Agagi, Y. Kanazawa and A. Nabae," A new approach to harmonic compensation in power systems", IEEE Trans. Ind. Appli. Vol. 26, pp. 983-990, 1990.

[4]. S. Bhattachararya, D. M. Divan and B. Banarjee, "Synchronous frame harmonic isolator using active series filter", EPE Conf. Firenze (Italy), vol. 3, pp. 30-35, 1991.

[5] K. Aliouane, S. Saadate and B. Davat, "Analytical study and numerical simulation of combined voltage source series active and shunt passive filters", IEEE International Symposium on Industrial Electronics Budapest (Hungrary), pp. 605-609, 1993.

[6] H. Fujita and H. Akagi, "A practical approach to harmonic compensation of passive and active filters", IEEE Trans. Appl. vol. 27, pp. 625-630, 1991.

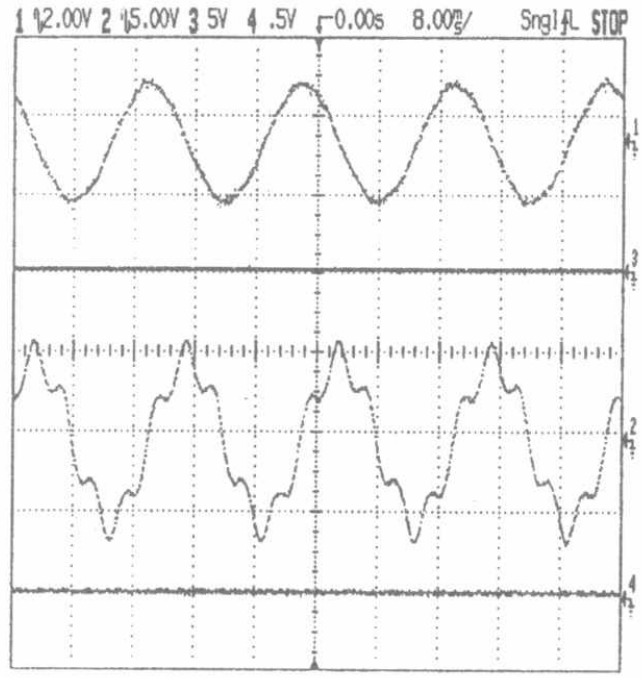

(a): : without active filter

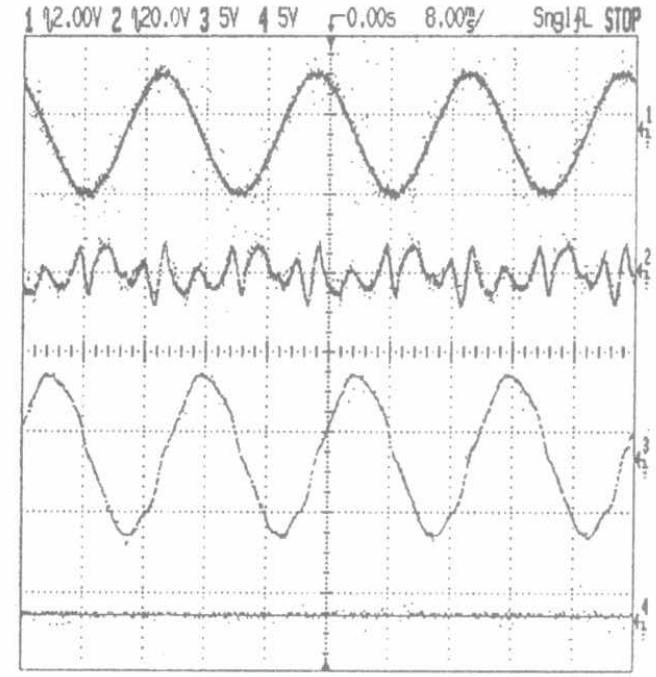

(b): : with active filter

Fig 10 : Experimental waveforms without load 


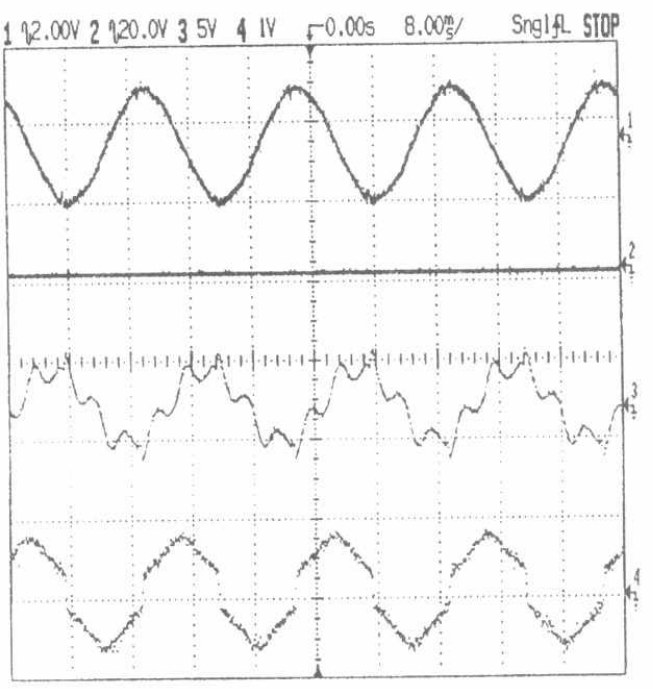

a): : without active filter

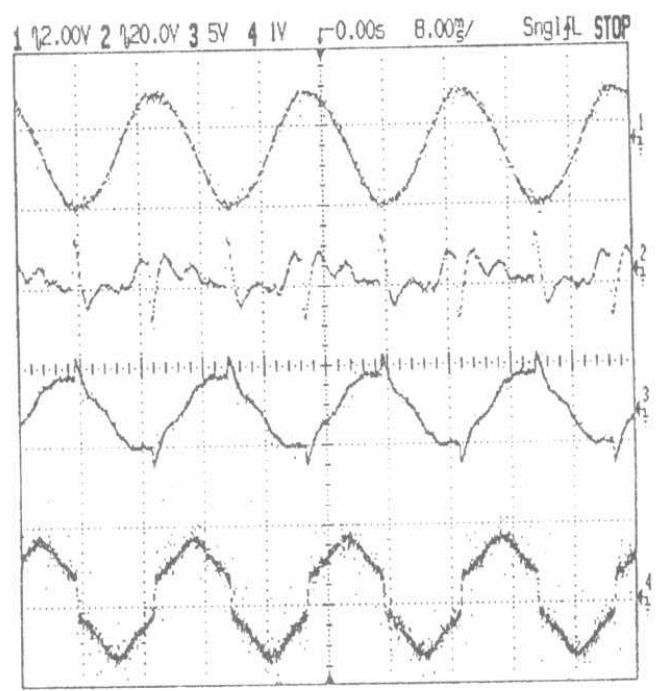

(b): : with active filter

Fig 11 : Experimental waveforms with load

From top to bottom :

passive filter voltage (360V/div)

active filter voltage (20V/div)

source current ( $8 \mathrm{~A} / \mathrm{div})$

load current (10A/div) 